\title{
Canadian Urological Association-Pediatric Urologists of Canada (CUA-PUC) guideline for the diagnosis, management, and followup of cryptorchidism
}

\author{
Luis H. Braga, MD'; Armando J. Lorenzo, MD²; Rodrigo L.P. Romao, $M D^{3}$
}

'Division of Urology, McMaster Children's Hospital and McMaster University, Hamilton, ON; ${ }^{2}$ Division of Urology, The Hospital for Sick Children and University of Toronto, Toronto, ON; ${ }^{3}$ Division of Urology, IWK Health Centre and Dalhousie University, Halifax, NS; Canada

Cite as: Can Urol Assoc J 2017;11(7):E251-60. http://dx.doi.org/10.5489/cuaj.4585 Published online July 11, 2017

\section{Introduction}

Cryptorchidism is one of the most common congenital anomalies in males, characterized by inability to palpate the testicle in the expected normal anatomical position (i.e., within its respective hemi-scrotum). It represents an abnormality of testicular descent and development associated with long-term concerns, including infertility, hypogonadism, and development of neoplasms.

\section{Methodology}

A search of MEDLINE, Cochrane, and EMBASE databases and conference proceedings (January 1988-December 2015) were included to evaluate data and select pertinent articles on the topic. Search terms included cryptorchidism or undescended testicle as the topic of interest with an English language limit. Retrospective and prospective study designs, case series, review articles, and consensus statements by relevant organizations were included.

Grading of evidence to base the presented summary guidelines followed the International Consultation on Urologic Disease (ICUD)/World Health Organization (WHO) modified Oxford Centre for Evidence-Based Medicine grading system (see inset).

\section{Epidemiology}

When assessed in the newborn period, incidence is somewhat variable, yet clearly dependent on gestational age at birth. Cryptorchidism is diagnosed in $1.0-4.6 \%$ of full-term and $1.1-45.3 \%$ of preterm male neonates. ${ }^{1}$ In up to one-third of cases, the condition may affect both gonads. ${ }^{2}$ Following spontaneous decent, often seen in the first 3-6 months of life, prevalence stabilizes at $0.7-1.0 \%$ of one-year-old boys.

\section{Definition of grades and levels of evidence ${ }^{\S}$}

\section{Levels}

1: Systematic review of randomized trials

2: Individual randomized trial

3: Controlled cohort

4: Case series or case control studies

5: Mechanism based reasoning

\section{Grades}

A: Consistent level 1

B: Consistent level 2 or extrapolation from level 1 or 3 studies

C: Level 4 studies or extrapolation from level 2 or 3 studies

D: Level 5 evidence or inconsistent/inconclusive studies of any level

$\S 0 x f o r d$ Centre for Evidence-based Medicine Levels of Evidence (May 2009). Produced by Bob Phillips, Chris Ball, Dave Sackett, Doug Badenoch, Sharon Straus, Brian Haynes, Martin Dawes since November 1998. Updated by Jeremy Howick March 2009. http://www.cebm.net/index.aspx?0=1025. Accessed November 7, 2013.

When patients with a normal exam or retractile testicles are excluded, approximately $75 \%$ of undescended testes are palpable and unilateral. ${ }^{3}$ Acquired cryptorchidism (or ascending testicles) is found in approximately $1.5 \%$ of prepubertal boys, with up to $77 \%$ showing spontaneous descent at puberty. ${ }^{4}$ These statistics demonstrate that cryptorchidism represents a common healthcare problem that translates into an important burden to the healthcare system. In order to maximize efficiency and timely correction, it demands a structured approach with appropriate use of resources, avoiding redundancies, unnecessary tests, or delays in treatment.

\section{Rationale for treatment}

The goals of treatment are summarized in Table 1. Surgical correction is offered early after diagnosis in order to maxi- 


\section{Important definitions and considerations}

Congenital vs. acquired cryptorchidism: Distinction based on findings documented during the neonatal exam. In congenital cases, the testicle is not palpable in the scrotum at birth, while an acquired cryptorchidism (or "ascending" testicle) is in a normal location at birth (or on subsequent well-child exams), but not later in life.

Retractile testis: Refers to a testicle that intermittently migrates to a higher location along the normal path of descent due to a brisk cremasteric reflex. On exam, the testicle can be manipulated to its normal location and remains there after releasing it.

"True" undescended vs. ectopic testes: Based on location (as determined during physical exam and/or surgery) within or outside the normal path of testicular descent, respectively. An ectopic testicle is unlikely to spontaneously descend or respond to hormonal stimulation.

Palpable vs. non-palpable testicle: Based on ability to feel the testicle during physical exam. If non-palpable, diagnostic considerations expand to intra-abdominal testicle, inaccurate exam, and testicular absence or atrophy (so-called "nubbin"). The diagnosis is commonly confirmed during exam under anesthesia and surgical exploration.

mize fertility potential and adequate hormone production by preventing acquired damage to gonadal tissue from being in an extra-scrotal position. In addition, exploration and orchidopexy aim to relocate viable testicular tissue outside of the abdomen in a position amenable to regular self-exam later in life, which aids in early diagnosis of testicular cancer. Surgical correction also decreases the risk of future testicular torsion and addresses associated abnormalities (such as a patent processus vaginalis or clinically evident hernia). Orchidopexy may also aid in preventing direct testicular trauma against the pelvic bones during intercourse or sports and provides psychological benefits by attempting to recreate normal anatomy.

\section{Long-term implications}

Reduced fertility

Any correlation of infertility with undescended testis (UDT) must be tempered by the fact that $15-20 \%$ of couples in the general Canadian population have difficulty conceiving, ${ }^{5}$ and there is often more than one factor involved. Paternity rates are largely unchanged for men with unilateral cryptorchidism compared to the general population (around 90\%), but are significantly lower (33-65\%) for those with bilateral UDT. ${ }^{6}$ Hence, only one-third to two-thirds of men with bilateral cryptorchidism will be able to father a child. In terms of

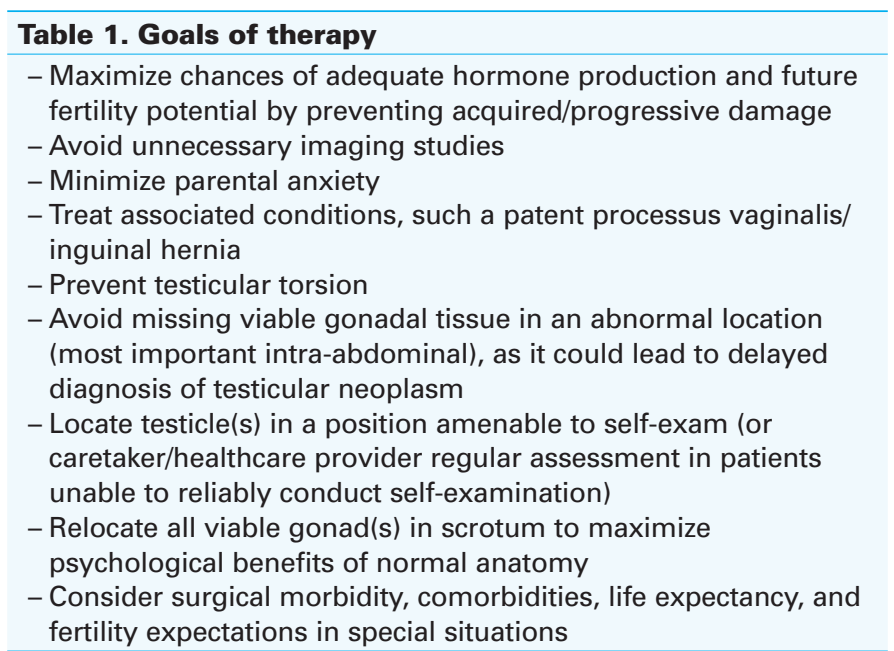

histology, there is evidence that both location of the testicle and time correlate with Leydig and germ cell loss. Intraabdominal/non-palpable testes depict severe germ cell loss, as do testes that remain undescended by the age of two years $^{7}$ (Level 3 evidence, Grade C recommendation).

\section{Risk of testicular cancer}

Testicular cancer is rare, with an incidence around 4/100 000 in Canada. ${ }^{8}$ There has long been an association noted between UDT and testicular malignancy, with $11 \%$ of testicular cancers developing in men with a history of UDT. Recent studies have found the relative risk (RR) of developing testicular cancer in a boy with UDT is $2.75-8,{ }^{9-11}$ corresponding to an absolute risk of 12-33 per $100000 .{ }^{9}$ The risk is slightly increased also in the normally descended testis. ${ }^{12}$ Performing orchiopexy prior to puberty appears to decrease the RR of subsequent testicular cancer to $\mathbf{2 . 2 3}$ (confidence interval $[\mathrm{CI}]$ 1.58-3.06), but it still remains above that of the normal non-cryptorchid male (Level 3 evidence, Grade B recommendation). ${ }^{9}$ Thus, we recommend that for patients with unilateral intra-abdominal and inguinal hypotrophic testes identified after puberty, orchiectomy be offered as an option (not mandatory) (Level 4 evidence, Grade D recommendation).

\section{Evaluation}

Early diagnosis is instrumental for determining adequate followup and timely referral for specialized assessment and treatment. Genital exam by an experienced healthcare provider with good documentation of testicular position should be conducted in all newborn males. In addition, the presence of associated genitourinary abnormalities (such as hypospadias and inguinal hernia) and ipsilateral scrotal hypoplasia ${ }^{13}$ should be assessed. Features suggestive of a 
disorder of sexual development (DSD) should trigger appropriate evaluation by a multidisciplinary team with expertise in these conditions (see below). In particular, a virilized newborn with bilateral non-palpable gonads should be considered to be 46XX with congenital adrenal hyperplasia until proven otherwise. In these babies, laboratory evaluation to rule out a salt-wasting condition should be expedited (and completed prior to discharge) in order to avoid morbidity and potential mortality. ${ }^{14}$

Even though cryptorchidism is most commonly diagnosed in otherwise healthy children, it is important to remember that it is a component of almost 400 syndromes, many with important comorbidities that often raise concerns for surgical correction when anesthetic risks, life expectancy, and realistic future fertility interests are considered. These issues should be openly discussed with parents or other caretakers supported by healthcare providers with expertise in the particular condition (such as geneticists and a complex care pediatrics team), and anesthetists for counselling regarding anesthesia risk. In addition, syndromes associated with high likelihood of intra-abdominal gonads (and low likelihood of spontaneous descent), such as Prune Belly or Eagle Barrett syndrome, should be detected early and considered in the management plan.

Aside from newborn screening, a carefully documented genital exam should be part of well-child visits and during the assessment of children with suspected hernia or hydrocele and unexplained abdominal or inguinal pain. Healthcare providers should remember that a normal exam in the newborn period does not rule out the future development of cryptorchidism (i.e., testicular ascent).

\section{Physical exam}

Evaluation by an experienced healthcare provider remains the most important component of the assessment of children with suspected cryptorchidism, allowing the distinction between a normally located gonad, retractile testicle, palpable undescended/ectopic testicle, and non-palpable testicle. Associated conditions, such as an inguinal hernia, are concomitantly evaluated. The exam should be performed in a quiet, warm environment, assisted with lubrication if needed, and focus on the inguinal canal and scrotum, along with less common ectopic sites (perineal, femoral, prepubic). Ultrasound evaluation is not a substitute for a wellperformed exam and it does not add diagnostic accuracy to an evaluation by a less experienced healthcare provider or a limited exam due to an uncooperative child.

In patients with unilateral cryptorchidism, evaluation of the contralateral gonad is important in order to detect potential problems with the normally located testicle (such as atrophy, varicocele, abnormal volume, or consistency for age). In addition, the presence of testicular hypertrophy (most often suspected when the axial length of the testicle is greater than $1.8-2 \mathrm{~cm}$ ), is associated with a higher likelihood of an absent or atrophic non-palpable gonad. This information is valuable to provide preoperative counselling and can help decide on surgical approach and allocation of operating room time.

\section{Imaging studies}

When ordering imaging studies for evaluating suspected cryptorchidism, the healthcare provider should take into consideration the following issues:

- Imaging studies that require sedation or anesthesia (such as magnetic resonance imaging, [MRI]), regardless of the diagnostic performance of the test, do not have any therapeutic value. Thus, under most circumstances, surgical exploration is not avoided and a second anesthetic will be required for treatment.

- The use of imaging modalities that employ ionizing radiation (such as computed tomography [CT] scans) should be avoided, since the information obtained does not change management. ${ }^{15,16}$ The additive exposure over the child's lifetime, along with delivery of radiation to gonadal tissue (which happens, by definition, as the goal is to localize it), adversely impacts any added value and supports discouraging this practice.

- None of the currently available imaging modalities have sufficient reproducible diagnostic accuracy to confidently rule out the presence of intra-abdominal viable gonadal tissue. Thus, ultimately, in most cases surgical exploration is not avoided. Imaging tests may have potential merit solely in directing the best initial approach (e.g. scrotal vs. inguinal vs. laparoscopic exploration).

- Inaccurate or incongruent diagnosis in comparison to physical exam adds uncertainty and may lead to suboptimal management. Clear examples include surgical intervention for retractile testicles diagnosed as cryptorchidism by ultrasound, foregoing surgical exploration and missing an intra-abdominal gonad based on lack of visualization in ultrasound, CT scan or MRI, and extensive surgical exploration in the setting of a false positive image suggesting the presence of an intra-abdominal gonad.

- The practice of systematically ordering imaging studies on children with cryptorchidism adds a significant burden on the healthcare system and increases healthcare expenditures with limited added value and may introduce delays in appropriate referral and timely treatment.

Based on the aforementioned points, imaging in cryptorchidism is not cost-effective, may delay referral and surgical 
Braga et al.

treatment, and as such cannot be recommended as a standard adjunct to preoperative assessment of these children (Level 3 evidence, Grade B recommendation).

Need for investigation for DSD, karyotype, and other biochemical/ genetic studies

The incidence of karyotype or other genetic abnormalities in boys with cryptorchidism is low (around 5\% for those with persistent cryptorchidism after six months and $8 \%$ for boys with bilateral UDT). ${ }^{17}$ Hence, routine karyotype or genetic workup of patients with UDT is NOT recommended (Level 4 evidence, Grade D recommendation).

Patients with bilateral non-palpable gonads and a normal phallus with an orthotopic urethral meatus should undergo a karyotype (and further hormonal testing of 17-hydroxy progesterone levels if XX karyotype found) to rule out congenital adrenal hyperplasia. ${ }^{18}$ Although the yield of such practice is low, we recommend it due to the potential devastating issues (salt-wasting crisis, gender assignment discussions) associated with a missed diagnosis.

In patients with bilateral non-palpable testicles and a normal phallus bearing an XY karyotype, the diagnosis of bilateral vanishing testicles or testicular regression syndrome (TRS) should be considered. In such patients, the combination of high gonadotropins, low testosterone levels (even after stimulation), and very low or undetectable levels of anti-Mullerian hormone may preclude any surgical intervention. ${ }^{19,20}$ In this specific scenario, we recommend consultation with an endocrinologist to determine the best management on an individual basis since interpretation of these investigations is complex and sometimes inconclusive.

Approximately one-third of patients with proximal hypospadias and at least one undescended testicle (particularly if non-palpable) have a DSD. ${ }^{21}$ DSD has not been observed in patients with the association of distal hypospadias and UDT. ${ }^{22}$ Therefore, we recommend performing a karyotype in patients with at least one undescended testicle and proximal hypospadias, especially in the setting of non-palpable gonads (Level 4 evidence, Grade D recommendation).

WT1 mutations have been identified in a single series of patients with the association of proximal hypospadias and at least one UDT in $6 / 80(7.5 \%)$ boys who were tested. ${ }^{23}$ Further development of renal disease and/or Wilms' tumour was documented in those patients. Hence, we recommend that consideration be given to include targeted WT1 genetic testing in patients that fit that profile (Level 3 evidence, Grade C recommendation).

Persistent Mullerian Duct Syndrome (PMDS) is suggested by the presence of Mullerian structures (uterus, fallopian tube) attached to an undescended testicle (more commonly intra-abdominal) and is usually an intraoperative finding. It is caused by a mutation on the gene that encodes either $\mathrm{AMH}$ or its receptor; such mutation is transmitted follow- ing an autosomal recessive trait. Rarely, PMDS can lead to both testicles occupying the same side of the abdomen (transverse testicular ectopia). Surgical removal of the Mullerian structures seems logical since malignancies have been reported and at times their attachments can hinder the performance of a tension-free orchidopexy. Removal can be achieved through open surgery or laparoscopically with care being taken not to damage the vas deferens, which can be quite adherent to the Mullerian structures. ${ }^{24,25}$ When Mullerian remnants are found incidentally during an inguinal orchidopexy, the proximal aspect of the fallopian tube can be transected and removed with the uterus, leaving its distal component attached to the vas deferens, allowing the testis to be brought to a scrotal position (Level 4 evidence, Grade D recommendation). Such maneuver avoids separation of the tube from the cord structures, protecting the deferential and testicular blood supply. Patients should have AMH levels checked and be referred to endocrinology/ genetics for investigation.

If a DSD is discovered, patients should be followed in a multidisciplinary clinic specific to these complex diagnoses.

\section{Management options (Fig. 1)}

\section{Hormonal stimulation/hormonal therapy}

Treatment of UDT with either human chorionic gonadotropin (hCG) or luteinizing hormone-releasing hormone $(\mathrm{LHRH})$ does not seem to cause harm and may be effective; however, reported success rates are inconsistent (9-62\%), with no single agent standing out. ${ }^{26}$ Bilateral cases seem to harbour the best response (25-30\%). ${ }^{27}$

There have been reports suggesting that administration of gonadotropin-releasing hormone $(\mathrm{GnRH})$ either pre or postorchidopexy may improve fertility based on improved fertility indices (ascertained by proxy with the ratio of adult spermatogonia per tubule on testicular biopsies taken at the time of orchidopexy). ${ }^{28-30}$ This is a highly controversial topic with conflicting recommendations having been published ${ }^{28,31}$ and should therefore be regarded as experimental.

There is paucity of data on long-term outcomes of hormone therapy, such as fertility and cancer development. ${ }^{26}$

Our recommendation is that hormone therapy has a limited role in the management of cryptorchidism and should not be recommended as first-line therapy (Level 2 evidence, Grade B recommendation).

\section{Surgical exploration}

\section{Timing}

There seems to be a general consensus regarding the ideal age for orchidopexy, although an evidence-based guideline 


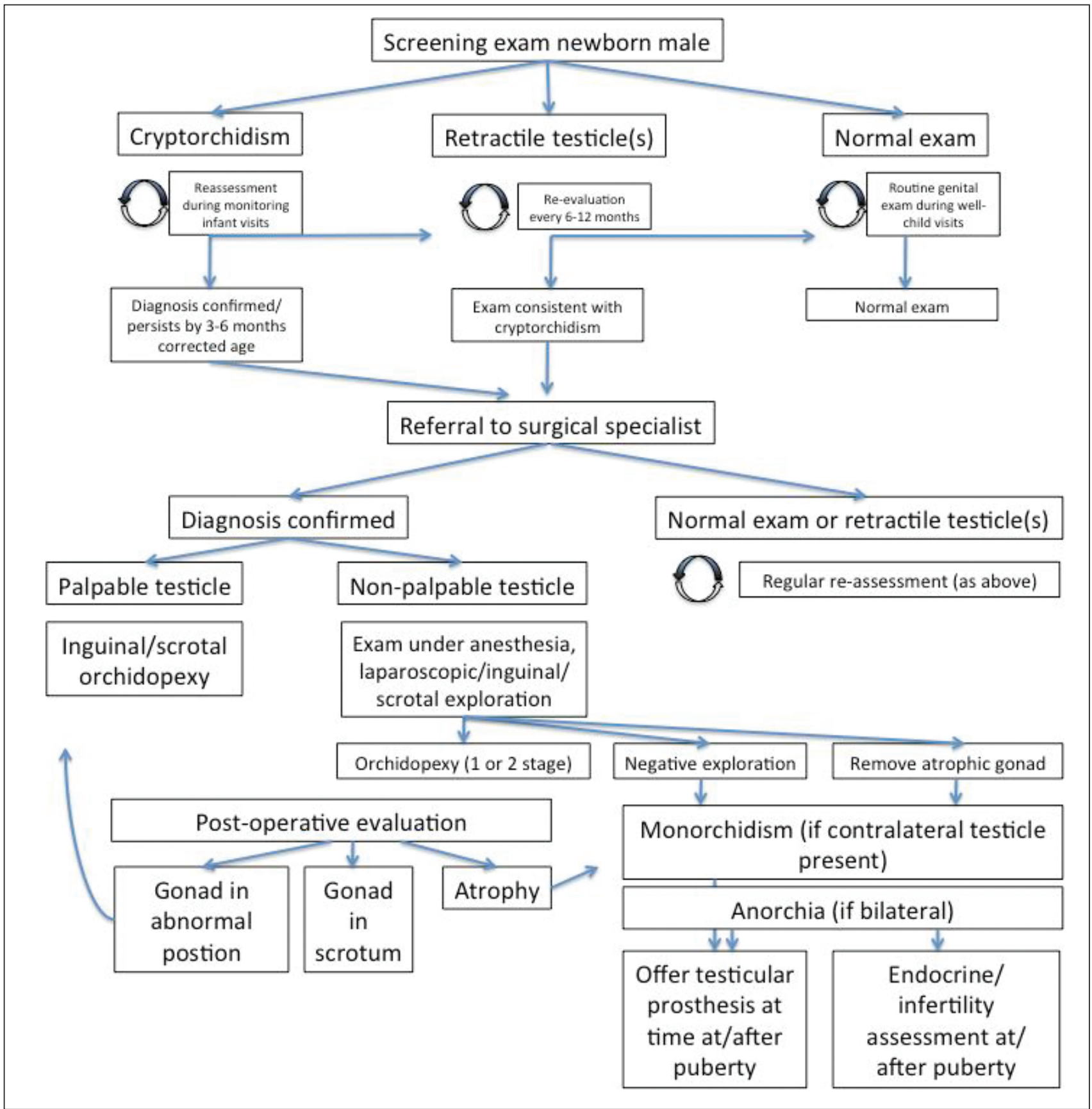

Fig. 1. Basic management algorithm for cryptorchidism diagnosed in infancy/early childhood.

is still lacking. According to the 1996 American Academy of Pediatrics recommendation ${ }^{32}$ and the recently published American Urological Associaton (AUA) guidelines ${ }^{33}$ on the topic, orchidopexy should be performed before one year of age based on changes in the number of germ cells in the UDT that start to occur beyond that age. ${ }^{34}$

Results from a randomized, controlled trial comparing testicular growth after surgery performed at nine months vs. at three years of age indicated that early orchidopexy was followed by a partial catch-up testicular growth, which was not seen after late operation. ${ }^{35}$ These findings, as well as the fact that testicular descent is unlikely to occur in full-term babies after six months of age, ${ }^{4}$ support our current recommendation of performing orchidopexy between six and 18 months of age (Level 2 evidence, Grade B recommendation). 
Braga et al.

\section{Orchidopexy techniques}

\section{Surgical approach to the palpable testicle}

\section{Inguinal orchidopexy}

Palpable testicles are approached most commonly through an inguinal incision. High (proximal) ligation of the processus vaginalis is an essential surgical step to allow placement of the testis in a sub-dartos pouch within the hemi-scrotum, without tension. Fixation sutures through the tunica albuginea can be used. The weighted success rate for primary inguinal orchidopexy was $96.4 \%$ based on a systematic review. ${ }^{26}$

\section{Scrotal orchidopexy}

The scrotal approach for management of cryptorchidism was first described by Bianchi in 1989, ${ }^{36}$ and has since gained wide acceptance. ${ }^{37-41}$ Evidence suggests that most palpable testicles can be successfully managed through this incision. ${ }^{37,38}$ According to a recent review that analyzed 1558 scrotal orchidopexies, recurrence was observed in only nine cases, testicular hypo/atrophy in five, and surgical site infections in 13. A secondary inguinal incision was needed in $3.5 \%$ of the boys to facilitate high (proximal) testicular dissection. Overall, success rates ranged from $88-100 \% .{ }^{42}$

In comparison to standard inguinal orchidopexy, recent evidence from observational studies has suggested that the scrotal approach has equivalent success rates and complications, with advantage of a significantly shorter operative time..$^{38,39,43}$ At least two randomized, controlled trials comparing the two techniques (inguinal vs. scrotal) have been attempted and essentially confirmed those findings; ${ }^{44,45}$ however, in one of the studies the authors also report mean length of stay above two days for both procedures, which questions the generalizability of the conclusions to our environment, where these procedures are almost universally undertaken on an outpatient basis. ${ }^{44}$ Furthermore, none of these randomized, controlled trials prespecified the minimal clinically important difference in operative time to justify sample size calculation; therefore, their conclusions should be interpreted with caution.

Our recommendation is that for palpable UDT undergoing surgery, both the inguinal and the prescrotal techniques are acceptable based on the surgeon's preference and experience (Level 2 evidence, Grade B recommendation).

\section{Surgical approach for the non-palpable testicle}

If the testicle is not palpable preoperatively, as it may occur in up to $20 \%$ of UDT cases, examination under anesthesia (EUA) can sometimes allow identification of the testicle. Otherwise, diagnostic laparoscopy is the procedure of choice in most centres. ${ }^{46}$ In certain non-palpable testicle
(NPT) cases, confident palpation of an ipsilateral scrotal nubbin and identification of contralateral compensatory testicular hypertrophy may preclude diagnostic laparoscopy by means of initially performing a scrotal incision, which allows for testicular nubbin removal and confirmation of the vanishing testicle diagnosis. ${ }^{47}$ Inguinal exploration and/ or laparoscopy can then be reserved for cases in which the initial scrotal approach is non-diagnostic.

The phenomenon of contralateral compensatory testicular hypertrophy has been well-described in the literature and shown to correlate with the laparoscopic finding of an absent testicle (monorchism) in children with unilateral NPT. ${ }^{4-10,14}$ Boys with monorchism were found to have a mean contralateral testicular length $>2 \mathrm{~cm}^{5}$ or $>1.8 \mathrm{~cm} .6,10$ Based on these findings, it could be debated that boys with NPT and contralateral compensatory hypertrophy should be initially approached by a scrotal incision to look for a testicular nubbin, reserving diagnostic laparoscopy only for cases with a patent processus vaginalis or lack of compensatory hypertrophy. ${ }^{47}$ It is critical to highlight the importance of confidently identifying atrophic testicular tissue with associated vas deferens and gonadal vessels if a scrotal or inguinal approach is chosen, as any doubt should trigger further exploration. Presence of a looping vas or incorrectly identifying non-gonadal tissue as a nubbin may lead to misdiagnosis, potentially leaving viable testicular tissue in the abdomen. In uncertain cases or when tissue analysis is not consistent with atrophic testicular tissue, laparoscopic exploration should be strongly considered (Level 4 evidence, Grade $\mathrm{C}$ recommendation).

If laparoscopy is unavailable, a lengthy inguinal incision extending to the abdominal cavity is sometimes necessary to rule out the presence of an intra-abdominal testicle. When a laparoscopic approach is chosen, up to three ports may be needed: a 3 or $5 \mathrm{~mm}$ umbilical trocar for the camera and two $3 \mathrm{~mm}$ ports for the working instruments. Single-port laparoscopic management for the intra-abdominal testicle has been described and constitutes an alternative option.

Diagnostic laparoscopy is the most useful modality for assessing NPT, as it permits identification of three surgical scenarios that will lead to different courses of action:

1. Blind-ending vas and vessels indicate a vanishing intra-abdominal testicle (IAT), and no further exploration is necessary (10-30\% of cases).

2. Testicular vessels and vas entering the inguinal canal through the internal inguinal ring. Inguinal exploration may find a healthy palpable UDT amenable to standard orchidopexy, or a testicular nubbin either in the inguinal region or, most commonly, in the scrotum. Remnant cord structures are usually removed to confirm the diagnosis and because viable residual testicular elements are present in up to $14 \%$ of the cases. ${ }^{48}$ It should be noted that to date, no cases of 
intratubular germ cell neoplasia have been reported within these specimens.

3. Peeping or IAT $(50 \%)$, which will require either an open or a laparoscopic orchidopexy in one or two stages.

Laparoscopy allows for accurate diagnosis of any of the three scenarios at the time of surgery, followed by the appropriate definitive management, i.e., orchidopexy in one or two stages or removal of nubbin/non-viable testis.

\section{Inguinal approach for the high inguinal canalicular, or IAT}

Bringing a high testicle down to the scrotum while preserving its blood supply can sometimes be a surgical challenge. Helpful maneuvers include division of the lateral fibrous attachments of the cord at the internal inguinal ring, blunt dissection of the retroperitoneal spermatic vessels (which are usually the limiting factor) up to the lower pole of the kidney, and mobilization of the cord medial to the inferior epigastric vessels (Prentiss maneuver). Despite these steps, if the testicle still does not reach the scrotum, a FowlerStephens (FS) orchidopexy may be performed. ${ }^{49}$

\section{Fowler-Stephens orchidopexy}

The FS technique was originally described as a single-stage open inguinal approach for the IAT in which the testicular artery and veins were too short to allow adequate testicular mobilization into the scrotum through standard orchidopexy. ${ }^{50}$ It involves ligating and dividing the testicular vessels while maintaining the normal pathway of testicular descent through the inguinal canal. The distal gubernacular attachments and the collateral vessels on the floor of the inguinal canal are left undisturbed, preserving the cremasteric blood supply. ${ }^{50}$

The laparoscopic FS orchidopexy entails division of the gonadal vessels and cremasteric collaterals during advancement of the IAT medial to the inferior epigastric vessels or obliterated umbilical artery. Despite its widespread use, ${ }^{51-54}$ either as a one- or two-stage procedure, atrophy rates can be as high as 33\%, probably due to failure of developing adequate collateral blood supply through the deferential artery. The presence of a long looping vas deferens may increase this risk, especially when the procedure is done laparoscopically ${ }^{55}$ In contrast, preservation of the gubernaculum during laparoscopic FS orchidopexy, mimicking one of the surgical steps of the open FS technique, may help decrease the likelihood of testicular atrophy. ${ }^{56-59}$

\section{Orchidopexy success rates of testicular descent}

Success rates of testicular descent are directly related to the anatomic position of the testicle. These rates range from $92 \%$ for standard inguinal open orchidopexy for testicles located below the external inguinal ring to $67 \%$ for one-stage laparoscopic FS orchidopexy for non-palpable testicles. ${ }^{60}$

A recent systematic review has compared the success rates of testicular descent for primary orchidopexy (palpable testes), one-stage, and two-stage FS procedures (non-palpable testes). According to this review, the weighted success rates for all three approaches exceeded $75 \%$. Independently, the overall success rates were $78.7 \%, 86 \%$, and $96.4 \%$ for one-stage FS, two-stage FS, and primary orchiopexy, respectively. ${ }^{26}$

\section{Open vs. laparoscopic orchidopexy for NPT}

Laparoscopic orchidopexy outcomes are comparable to those of open surgery. ${ }^{61,62}$ Based on a randomized, controlled trial that compared outcomes after two-stage laparoscopic FS orchidopexy vs. open orchidopexy for NPT, patients who underwent the laparoscopic approach were noticed to have statistically significantly shorter operative time and return to normal activities. Although all testicles in both groups were noted to have satisfactory scrotal position after surgery, two $(10 \%)$ of the 20 testes in the laparoscopic arm and three $(19 \%)$ of the 16 testes in the open group had atrophied after one year of followup. ${ }^{63}$

\section{Complications}

The most alarming complication of inguinal orchidopexy is testicular atrophy, which occurs when the testicular vessels are damaged. According to a recent systematic review on this topic, ${ }^{26}$ pooled atrophy rates were $1.83 \%$ for primary orchidopexy (range $0-4 \%$ ), $28.1 \%$ for one-stage FS (range $22-67 \%$ ), and $8.2 \%$ for two-stage FS (range 0-12\%). Similarly, another study has shown that surgical outcomes for IAT were better with a one-stage orchidopexy preserving the testicular vessels as opposed to the one-stage FS technique. ${ }^{64}$

Rare complications include testicular ascent, where the testicle gets pulled to the entrance of the scrotum, and vas deferens injury. Other orchidopexy related complications might include those associated with any surgical procedure, such as wound infection, dehiscence, and hematoma.

\section{Prophylatic contralateral orchidopexy}

Preventive orchidopexy of the normally descended contralateral testicle in the setting of blind-ending spermatic vessels found upon exploration of a non-palpable testis has been advocated by some authors. This is based on the reported risk of bell-clapper deformity and abnormal testicular fixation found in the remaining solitary testis (Bellinger 1985, Savage 2001). The risk of torsion is admittedly low, conceptually not different from the general population. Thus, any potential benefit must be weighed against the risk of damage to the solitary gonad during surgery. In the absence of literature 
Braga et al.

strongly supporting or discouraging prophylactic orchidopexy, the decision should be made based on informed discussion of options with the patient parents or legal guardian (Level 5 evidence, Grade D recommendation).

\section{Testicular biopsy}

Testicular biopsy is not indicated at the time of orchidopexy. Recent evidence has shown that total germ cell histopathology at the time of orchiopexy was not predictive of significant changes in hormone levels or semen analysis results in adulthood. ${ }^{49}$ According to these authors, it may be clinically useful in predicting fertility potential for those with bilateral undescended testicles, but this approach remains investigational. ${ }^{49}$

\section{Orchiectomy}

Orchiectomy remains the treatment of choice for the majority of postpubertal males presenting with unilateral cryptorchidism, especially when these testicles are small in size (hypotrophic/atrophic). Histological analysis of cryptorchid testicles in postpubertal patients has shown that most of these testes have significant malignant potential and cannot contribute to fertility (Sertoli only syndrome). ${ }^{65}$

\section{Conservative management}

UDT is associated with a multitude of syndromes, some of which can lead to limited life expectancy and/or severe developmental delay (e.g., Down's, Prader-Willi, and Noonan's syndromes). Furthermore, there is evidence that in many of these patients, testicular function suffers progressive deterioration over time. ${ }^{66}$ Nonetheless, given the reports of testicular cancer (sometimes at an early age ${ }^{67}$ ) in these patients, we recommend orchidopexy when they are clinically fit for anesthesia for the purpose of surveillance (Level 4 evidence, Grade D recommendation).

\section{Previously failed orchidopexy}

Overall orchidopexy failure rates are low (around 10\%), ${ }^{68}$ especially when only pediatric referral centre results are considered $(1-2 \%) .{ }^{69}$ When faced with a testicle in an inadequate (high) position after orchidopexy, redo surgery offers high success rates in terms of bringing the testicle to a scrotal position. ${ }^{68,69}$ Data on long-term (functional) outcomes of such testes are non-existent. We recommend offering redo orchidopexy for cases where inadequate position is detected postoperatively (Level 5 evidence, Grade D recommendation).

\section{Followup}

Although UDT are unquestionably associated with a higher risk for development of testicular cancer, the incidence rates of this type of cancer are small and hence no screening policy is justified. There is no need for formal long-term urological followup of patients with UDT. Nonetheless, periodic self-exam after puberty is recommended with prompt referral to an urologist if an abnormality is noted.

\section{Age at which orchiectomy is advisable over orchidopexy}

Data suggest that the risk of malignancy within a postpubertal UDT is higher compared to those that underwent prepubertal orchidopexy. ${ }^{70}$ Additionally, testicular cancer is exceedingly rare in older adults (i.e., after 50 years of age). ${ }^{9,71}$ Hence, we recommend considering orchiectomy for postpubertal patients with hypotrophic/atrophic undescended testicles up to the age of 50 . After that age, observation is likely appropriate (Level 4 evidence, Grade D recommendation).

\section{Acquired cryptorchidism}

Acquired UDT are diagnosed at an average age of 8-11 years. The reasons for this late diagnosis remain unknown. Careful serial physical examination is recommended to accurately determine testicular position and identify cases of acquired cryptorchidism in boys with retractile testes. Some authors believe that acquired UDT represent a milder subtype of congenital cryptorchidism that has escaped detection in infancy. ${ }^{72}$ The percentage of retractile testicles that ascends and requires orchidopexy is difficult to estimate, ranging from $3-30 \%$ in prepubertal children. ${ }^{73}$ Based on that, it is difficult to set a specific age for correction of these cases because it may vary from child to child.

Competing interests: The authors report no competing personal or financial interests.

This paper has been peer-reviewed.

\section{References}

1. Sijstermans K, Hack WWM, Meijer RW, et al. The frequency of undescended testis from birth to adulthood: A review. Int J Androl 2008;31:1-11.

2. Berkowitz GS, Lapinski RH, Dolgin SE, et al. Prevalence and natural history of cryptorchidism. Pediatrics 1993;92:44-9.

3. Cendron M, Huff DS, Keating MA, et al. Anatomical, morphological and volumetric analysis: A review of 759 cases of testicular maldescent. J Urol 1993;149:570-3.

4. Hack WWM, van der Voort-Doedens $L M$, Goede J, et al. Natural history and long-term testicular growth of acquired undescended testis after spontaneous descent or pubertal orchidopexy. BJU Int 2010;106:10529. hitps://doi.org/10.1111/i.1464-410X.2010.09226.x

5. Health Canada. Ferility in Canada [nternet]. Government of Canada; [cited 2014 Nov]. Available from: http:// healthycanadians.gc.ca/healthy-living-vie-saine/pregnancy-grossesse/fert-eng.php. Accessed June 1, 2017. 
6. Lee PA. Fertility after cryptorchidism: Epidemiology and other outcome studies. Urology 2005;66:427-31 https://doi.org/10.1016/i.urology.2005.01.017

7. Tasian GE, Hittelman AB, Kim GE, et al. Age at orchiopexy and testis palpability predict germ and Leydig cell loss: Clinical predictors of adverse histological features of cryptorchidism. J Urol 2009;182:704-9. https://doi.org/10.1016/i.juro.2009.04.032

8. Garner MJ, Turner MC, Ghadirian P, et al. Epidemiology of testicular cancer: An overview. Int I Cancer 2005;116:331-9. https://doi.org/10.1002/iic.21032

9. Wood HM, Elder JS. Cryptorchidism and testicular cancer: Separating fact from fiction. J Urol 2009;181:452-61. https://doi.org/10.1016/i.juro.2008.10.074

10. Cook MB, Akre 0 , Forman $D$, et al. A systematic review and meta-analysis of perinatal variables in relation to the risk of testicular cancer—experiences of the son. Int J Epidemiol 2010;39:1605-18. https://doi.org/10.1093/iie/dyq120

11. Trabert B, Zugna D, Richiardi L, et al. Congenital malformations and testicular germ cell tumours. Int J Cancer 2013;133:1900-4. https://doi.org/10.1002/iic.28207

12. Akre 0, Pettersson A, Richiardi L. Risk of contralateral testicular cancer among men with unilaterally undescended testis: A meta-analysis. Int J Cancer 2009;124:687-9. hitps://doi.org/10.1002/iic.23936

13. Snodgrass $W$, Bush $N$, Holzer $M$, et al. Current referral patterns and means to improve accuracy in diagnosis of undescended testis. Pediatrics 2011;127:e382-8. https://doi.org/10.1542/peds.2010-1719

14. White PC. Neonatal screening for congenital adrenal hyperplasia. Nat Rev Endocrinol 2009;5:490-8. hrtps://doi.org/10.1038/nrendo.2009.148

15. Mathews JD, Forsythe AV, Brady Z, et al. Cancer risk in 680000 people exposed to computed tomography scans in childhood or adolescence: Data linkage study of 11 million Australians. BMJ 2013;346:\{2360. https://doi.org/10.1136/bmi.f2360

16. Miglioretti DL, Johnson E, Williams A, et al. The use of computed tomography in pediatrics and the associated radiation exposure and estimated cancer risk. Laparoscopic management of persistent mullerian duct syndrome. JAMA Pediatr 2013;167:700-7. https://doi.org/10.1001/jamapediatrics.2013.311

17. Ferlin A, Zuccarello D, Zuccarello B, et al. Genetic alterations associated with cryptorchidism. JAMA 2008;300:2271-6. https://doi.org/10.1001/jama.2008.668

18. Krill EA, Karnak , Ciftci AO, et al. An unexpected diagnosis in children with male phenotype and bilateral non-palpable gonad: Congenital adrenal hyperplasia with female genotype. Ped Surgery Int 2013;29:71924. https://doi.org/10.1007/s00383-013-3319-3

19. Teo AQA, Khan AR, Williams MPL, et al. Is surgical exploration necessary in bilateral anorchia? J Pediatr Urol 2013;9:e78-81. htrps://doi.org/10.1016/i.jpurol.2012.09.006

20. Lee MM, Donahoe PK, Silverman BL, et al. Measurements of serum müllerian inhibiting substance in the evaluation of children with non-palpable gonads. N Engl J Med 1997;336:1480-6. https://doi.org/10.1056/NEJM199705223362102

21. Kaefer $M$, Diamond D, Hendren WH, et al. The incidence of intersexuality in children with cryptorchidism and hypospadias: Stratification based on gonadal palpability and meatal position. J Urol 1999;162:10036; discussion 1006-7.

22. Cox MJ, Coplen DE, Austin PF. The incidence of disorders of sexual differentiation and chromosomal abnormalities of cryptorchidism and hypospadias stratified by meatal location. J Urol 2008;180:264952; discussion 2652.

23. Köhler B, Biebermann H, Friedsam V, et al. Analysis of the Wilms' tumour suppressor gene (WT1) in patients 46, XY disorders of sex development. J Clin Endocrinol Metab 2011;96:E1131-6. https://doi.org/10.1210/ic.2010-2804

24. Parelkar SV, Gupta RK, Oak S, et al. Laparoscopic management of persistent Mullerian duct syndrome. J Pediatr Surg 2009;44:el-3. https://doi.org/10.1016/i.jpedsurg.2009.05.033

25. Farikullah J, Ehtisham S, Nappo S, et al. Persistent Mullerian duct syndrome: Lessons learned from managing a series of eight patients over a 10-year period and review of literature regarding malignant risk from the Mullerian remnants. BJU Int 2012;110:E1084-9. https://doi.org/10.1111/i.1464410X.2012.11184.x

26. Penson D, Krishnaswami S, Jules A, et al. Effectiveness of hormonal and surgical therapies for cryptorchidism: A systematic review. Pediatrics 2013;131:e1897-907. https://doi.org/10.1542/peds.2013-0072

27. Christiansen P, Müller J, Buhl S, et al. Treatment of cryptorchidism with human chorionic gonadotropin or gonadotropin-releasing hormone. A double-blind controlled study of 243 boys. Horm Res 1988;30:187-92. https://doi.org/10.1159/000181058

28. Biers SM, Malone PS. A critical appraisal of the evidence for improved fertility indices in undescended testes after gonadotrophin-releasing hormone therapy and orchidopexy. J Pediatr Urol 2010;6:239-46. https://doi.org/10.1016/i.jpurol.2010.02.203

29. Jallouli M, Rebai T, Abid N, et al. Neoadjuvant gonadotropin-releasing hormone therapy before surgery and effect on fertility index in unilateral undescended testes: A prospective, randomized trial. Urology 2009;73:1251-4. https://doi.org/10.1016/j.urology.2008.10.078

30. Schwentner C, Oswald J, Kreczy A, et al. Neoadjuvant gonadotropin-releasing hormone therapy before surgery may improve the fertility index in undescended testes: A prospective, randomized trial. J Urol 2005;173:974-7. https://doi.org/10.1097/01.ju.0000153562.07287.77
31. Ritzén EM. Undescended testes: A consensus on management. Eur J Endocrinol 2008;159 Suppl 1:S8790. https://doi.org/10.1530/EJE-08-0181

32. American Academy of Pediatrics. Timing of elective surgery on the genitalia of male children with particular reference to the risks, benefits, and psychological effects of surgery and anesthesia. Pediatrics 1996;97:590-4.

33. Kolon TF, Herndon CA, Baker LA, et al. Evaluation and treatment of cryptorchidism: AUA guideline. J Urol 2014;192:337-45. hitps://doi.org/10.1016/i.juro.2014.05.005.

34. Hutson JM, Li R, Southwell BR, Petersen BL, et al. Germ cell development in the postnatal testis: The key to prevent malignancy in cryptorchidism? Front Endocrinol (Lausanne) 2012;3:176.

35. Kollin C, Karpe B, Hesser U, et al. Surgical treatment of unilaterally undescended testes: Testicular growth after randomization to orchiopexy at age nine months or three years. J Urol 2007;178:158993; discussion 1593.

36. Bianchi A, Squire BR. Transscrotal orchidopexy: Orchidopexy revised. Ped Surgery Int 1989;4:189-92.

37. Gordon M, Cervellione RM, Morabito A, et al. 20 years of transcrotal orchidopexy for undescended testis: Results and outcomes.J Pediatr Urol 2010;6:506-12. https://doi.org/10.1016/i.jpurol.2009.10.016

38. Callewaert PRH, Rahnama'i MS, Biallosterski BT, et al. Scrotal approach to both palpable and impalpable undescended testes: should it become our first choice? Urology 2010;76:73-6. https://doi.org/10.1016/i.urology.2009.09.096

39. Yucel S, Celik 0 , Kol A, et al. Initial prescrotal approach for palpable cryptorchid testis: Results during a three-year period. J Urol 2011;185:669-72. https://doi.org/10.1016/i.juro.2010.09.117

40. Bassel YS, Scherz HC, Kirsch AJ. Scrotal incision orchiopexy for undescended testes with or without a patent processus vaginalis. J Urol 2007;177:1516-8. https://doi.org/10.1016/i.juro.2006.11.075

41. Cloutier J, Moore K, Nadeau G, et al. Modified scrotal (Bianchi) mid-raphe single incision orchiopexy for low palpable undescended testis: Early outcomes. J Urol 201 1;185:1088-92. https://doi.org/10.1016/i. juro.2010.10.039

42. Novaes HFF, Carneiro Neto JA, Macedo A, et al. Single scrotal incision orchiopexy—a systematic review. Int Braz J Urol 2013;39:305-11. https://doi.org/10.1590/S1677-5538.IBJU.2013.03.02

43. Al-Mandil M, Khoury AE, et al. Potential complications with the prescrotal approach for the palpable undescended testis? A comparison of single prescrotal incision to the traditional inguinal approach. J Urol 2008;180:686-9. https://doi.org/10.1016/i.juro.2008.04.040

44. Na SW, Kim S-0, Hwang EC, et al. Single scrotal incision orchiopexy for children with palpable lowlying undescended testis: Early outcome of a prospective, randomized, controlled study. Korean I Urol 2011;52:637-41. https://doi.org/10.4111/kju.2011.52.9.637

45. Nazem M, Hosseinpour M, Shahbandari M. Evaluation of orchidopexy with or without opening the external oblique fascia in children with superficial inguinal undescended testis. Eur J Pediatr Surg 2011;21:255-7. https://doi.org/10.1055/s-0031-1275724

46. Cisek $\mathrm{U}$, Peters $\mathrm{CA}$, Atala A, et al. Current findings in diagnostic laparoscopic evaluation of the non-palpable testis. J Urol 1998;160:1145-91; discussion 1150.

47. Snodgrass WT, Yucel S, Ziada A. Scrotal exploration for unilateral non-palpable testis. J Urol 2007;178:1718-21. https://doi.org/10.1016/i.juro.2007.05.089

48. Storm D, Redden T, Aguiar M, et al. Histological evaluation of the testicular remnant associated with the vanishing testes syndrome: Is surgical management necessary? Urology 2007;70:1204-6. https://doi. org/10.1016/i.urology.2007.08.020

49. Kirsch AJ, Escala J, Duckett JW, et al. Surgical management of the non-palpable testis: The Children's Hospital of Philadelphia experience. J Urol 1998;159:1340-3. https://doi.org/10.1016/S0022$5347(01) 63613-9$

50. Fowler R, Stephens FD. The role of testicular vascular anatomy in the salvage of high undescended testes. Aust N Z J Surg 1959;29:92-106. https://doi.org/10.1111/i.1445-2197.1959.tb03826.x

51. Baker LA, Docimo SG, Surer I, et al. A multi-institutional analysis of laparoscopic orchidopexy. BJU Int 2001;87:484-9. https://doi.org/10.1046/j.1464-410X.2001.00127.x

52. Esposito C, Caldamone AA, Settimi A, et al. Management of boys with non-palpable undescended testis. Nat Clin Pract Urol 2008;5:252-60. https://doi.org/10.1038/ncpurol 102

53. Caldamone AA, Amaral JF. Laparoscopic stage 2 Fowler-Stephens orchiopexy. J Urol 1994;152:1253-6.

54. Dénes FT, Saito FJ, Silva FA, et al. Laparoscopic diagnosis and treatment of non-palpable testis. Int Braz J Urol 2008;34:329-34; discussion 335.

55. Dave S, Manaboriboon N, Braga LHP, et al. Open vs. laparoscopic staged Fowler-Stephens orchiopexy: Impact of long loop vas. J Urol 2009;182:2435-9. https://doi.org/10.1016/i.juro.2009.07.050

56. Robertson SA, Munro FD, Mackinlay GA. Two-stage Fowler-Stephens orchidopexy preserving the gubernacular vessels and a purely laparoscopic second stage. J Laparoendosc Adv Surg Tech A 2007;17:101-7. https://doi.org/10.1089/lap.2006.0565

57. Braga LH, DeMaria J. Laparoscopic orchidopexy preserving the cremasteric vessels and using the inguinal canal as a pathway for testicular descent. Can Urol Assoc J 2009;3:560.

58. DeMaria J. Surgical maneuvers to improve testicular survival after a single stage Fowler-Stephens orchidopexy. Poster Presentation. Annual Congress of the European Society of Pediatric Urology. 2003. 
Braga et al.

59. Hay SA. Collateral circulation after spermatic vessel ligation for abdominal testis and its impact on staged laparoscopically assisted orchiopexy. J Laparoendosc Adv Surg Tech A 2007;17:124-7. https://doi.org/10.1089/lap.2006.0508

60. Docimo SG. The results of surgical therapy for cryptorchidism: A literature review and analysis. J Urol 1995;154:1148-52. https://doi.org/10.1016/S0022-5347(01)67015-0

61. Ferro F, Spagnoli A, Zaccara A, et al. Is preoperative laparoscopy useful for impalpable testis? J Urol 1999;162:995-6; discussion 997.

62. Chandrasekharam WVSS. Laparoscopy vs. inguinal exploration for non-palpable undescended testis. Indian J Pediatr 2005;72:1021-3. https://doi.org/10.1007/BF02724403

63. Abolyosr A. Laparoscopic vs. open orchiopexy in the management of abdominal testis: A descriptive study. Int J Urol 2006;13:1421-4. https://doi.org/10.1111/i.1442-2042.2006.01582.x

64. Moursy EE, Gamal W, Hussein MM. Laparoscopic orchiopexy for non-palpable testes: Outcome of two techniques. J Pediatr Urol 2011;7:178-81. https://doi.org/10.1016/i.jpurol.2010.04.010

65. Rogers $E$, Teahan $S$, Gallagher $H$, et al. The role of orchiectomy in the management of postpubertal cryptorchidism. J Urol 1998;159:851-4. https://doi.org/10.1016/S0022-5347(01)63752-2

66. Ankarberg-Lindgren C, Westphal 0, Dahlgren J. Testicular size development and reproductive hormones in boys and adult males with Noonan syndrome: A longitudinal study. Eur J Endocrinol 2011;165:137-44. https://doi.org/10.1530/EJE-11-0092
67. Dada R, Kumar R, Kucheria K. A two-year-old baby with Downs syndrome, cryptorchidism, and testicular tumour. Eur J Med Genet 2006;49:265-8. https://doi.org/10.1016/i.eimg.2005.08.002

68. Noseworthy J. Recurrent undescended testes. Semin Pediatr Surg 2003;12:90-3. https://doi.org/10.1016/S1055-8586(02)00017-3

69. McIntosh LA, Scrimgeour D, Youngson GG, et al. The risk of failure after primary orchidopexy: An 18-year review. J Pediatr Urol 2013;9:759-62. https://doi.org/10.1016/i.jpurol.2012.09.002

70. Walsh TJ, Dall'Era MA, Croughan MS, et al. Prepubertal orchiopexy for cryptorchidism may be associated with lower risk of testicular cancer. J Urol 2007;178:1440-6; discussion1446. https://doi.org/10.1016/i.juro.2007.05.166

71. Oh J, Landman J, Evers A, et al. Management of the postpubertal patient with cryptorchidism: An updated analysis. J Urol 2002;167:1329-33. https://doi.org/10.1016/S0022-5347(05)65293-7

72. Barthold JS, Gonzalez R. The epidemiology of congenital cryptorchidism, testicular ascent, and orchiopexy. J Urol 2003;170:2396-401. https://doi.org/10.1097/01.ju.0000095793.04232.d8

73. Stec AA, Thomas JC, DeMarco RT, et al. Incidence of testicular ascent in boys with retractile testes. J Urol 2007;178:1722-4. https://doi.org/10.1016/i.jur0.2007.05.091

Correspondence: Dr. Luis H. Braga, Division of Urology, McMaster Children's Hospital and McMaster University, Hamilton, ON, Canada; hpbraga@gmail.com

\section{Appendix 1. Summary of recommendations}

Physical exam is the cornerstone of cryptorchidism evaluation, and should be conducted by an experienced healthcare provider in a warm, relaxed environment

Documentation in patients with cryptorchidism should include history of prematurity, scrotal asymmetry, if the gonad(s) is palpable or not, and associated genitourinary abnormalities (such as hypospadias)

Phenotypic males with bilateral non-palpable gonads should raise the index of suspicion of congenital adrenal hyperplasia with a $46 \mathrm{XX}$ karyotype (along with other disorders of sexual development), and appropriate workup should be conducted prior to discharge to rule out a salt-wasting condition

If cryptorchidism is documented on newborn exam, regular monitoring is warranted to assess for spontaneous descent, and appropriate referral for specialized evaluation should be secured at or before six months of corrected age

Imaging studies, such as ultrasound, computed tomography scan or magnetic resonance imaging, are unnecessary, expensive, potentially misleading, and not warranted. They can be selectively ordered after specialist evaluation, including patients with suspected disorder of sexual development, and prior to surgical intervention at the discretion of the specialist

Unless the child has important comorbidities or high anesthetic risk, there is no role for conservative (i.e., expectant) management in children diagnosed with cryptorchidism past six months corrected age

Children with retractile testicle(s) should be regularly examined and the location of the gonad in the absence of an active cremasteric reflex clearly documented. If noted to ascend into an ectopic/undescended location, specialist referral is warranted

Acute abdominal/inguinal pain in a child with cryptorchidism should be considered a possible torsion and trigger appropriate urgent surgical assessment. A genital exam indicating the presence and location of the testicles should be documented in all boys with abdominal/ inguinal pain

Hormonal therapy has an unknown impact on subsequent gonadal function and has no advantage over timely surgical correction

There is no role for medical (hormonal) or surgical intervention(s) for children with retractile testicle(s)

Palpable undescended testicles can be addressed through a prescrotal or inguinal approach, based on location of the gonad and the ability to manipulate into the scrotum, as well as surgeon preference and expertise

If the testicle is not palpable on preoperative physical evaluation, an exam under-anesthesia should be conducted at the beginning of surgical exploration, as in 10-15\% of patients the gonad may become palpable and surgical approach can be appropriately tailored The goal of orchidopexy is to locate the gonad in its normal anatomical position, which should be documented on a postoperative followup assessment

Surgical procedures should address associated abnormalities, such as a patent processus vaginalis or hernia

The role of contralateral prophylactic orchidopexy in unilateral cryptorchidism or monorchidism (to prevent future testicular torsion) is controversial. The rationale for conducting this procedure or not should be disclosed to the family and appropriate warnings given to all families regarding the need for emergent evaluation in case of acute testicular pain

The diagnosis of an absent, vanishing, or atrophic testicle is based on surgical exploration. Surgical findings (including the presence of blind ending vas deferens and vessels, absence of testicle or nubbin), and/or pathological evaluation (hemosiderin, testicular tissue, vas deferens, and vessels) should be clearly documented in order to avoid future concerns and need for re-assessment

All patients should receive appropriate teaching regarding regular testicular self-exam following orchidopexy and need to alert healthcare providers if palpable abnormalities are noted or if a sudden increase in testicular size is perceived.

Patients should be referred for endocrine assessment in cases of delayed puberty and offered evaluation by an infertility specialist if concerned about future fertility potential. This recommendation in particularly important for boys at high risk for hormonal or fertility problems, such as those with bilateral intra-abdominal testicles, cryptorchidism in a solitary gonad, or concern about atrophy after attempted orchidopexy 